\title{
Developmental Orthopaedics. II: The Spine, Trauma and Infection
}

\section{Torticollis}

Torticollis, or wryneck, is a common clinical sign in a wide variety of childhood illnesses. When recognized at or soon after birth, the usual cause is congenital muscular torticollis. However, roentgenograms of the cervical spine should be obtained to exclude other less common congenital conditions, such as the fixed or bony torticollis associated with Klippel-Feil syndrome and/or anomalies of the atlanto-axial articulation (Table I).

Congenital muscular torticollis is usually discovered in the first six to eight weeks of life. If the infant is examined within the first month of life, commonly a mass or 'tumor' is palpable in the neck' (Fig. 1). Generally there is a non-tender, soft enlargement which is mobile beneath the skin and attached to or located within the body of the sternocleidomastoid muscle. The mass obtains maximum size within the first month and then gradually regresses. If the child is examined at about four to six months of age the tumor usually will have disappeared and the only clinical findings are the contracture of the sternocleidomastoid muscle and torticollis posture-head titled towards the involved side and chin rotated towards the opposite shoulder $^{2,3}$ (Fig. 2).
Congenital muscular torticollis is believed to result from local trauma to the soft tissues of the neck during delivery. Birth records of these children demonstrate a preponderance of breech or difficult forceps deliveries, or primiparous births ${ }^{1,4}$. A common misconception is that the neck is contused during delivery and the resultant hematoma leads to fibrosis and contracture. However, experimental

TABLE I

Differential diagnosis of torticollis
Congenital

Congenital muscular torticollis

Klippel-Feil syndrome

Basilar impressions

Atlanto-occipital fusion

Pterygium colli (skin webs)

Odontoid anomalies

Neurological

Ocular dysfunction

Syringomyelia

Spinal-cord or cerebellar tumors (posterior fossa)

Bulbar palsies

\section{Inflammatory}

Lymphadenitis of the neck

Spontaneous hyperemic atlanto-axial rotary subluxation

\section{Trauma}

Fractures, subluxation, dislocations of the cervical spine (particularly C1-2)

Correspondence to Robert N. Hensinger, M.D., Associate Professor of Orthopaedic Surgery, University of Michigan, University Hospital, Ann Arbor, Michigan 48109. 
work suggests that the fibrosis within the muscle is due to venous occlusion from pressure on the neck in the birth canal ${ }^{3,5}$. The clinical deformity is probably related to the ratio of fibrosis to remaining functional muscle after the initial insult ${ }^{2}$. If there is sufficient normal muscle it will stretch with growth and the child will not develop the torticollis posture. The fibrotic area, however, has little elastic potential. Further support for intra-uterine molding is provided by additional factors: in three out of four children the lesions are on the right side, ${ }^{1,3}$ and 20 per cent of affected children have congenital dysplasia of the hip $^{6}$.

All children with torticollis should be evaluated with roentgenograms to exclude bony abnormality or fracture. Congenital muscular torticollis is painless and is associated with a contracted or shortened sternocleidomastoid muscle, and it is not accompanied by bony abnormalities or neurological deficit.

\section{Congenital scoliosis}

Although congenital scoliosis seldom poses a serious problem for the neonate, early recognition of a vertebral anomaly is important. If not controlled, it can quickly lead to significant deformity, both cosmetic and life-threatening ${ }^{7}$ (Fig. 3a). In the neonate, there may be no visible curvature to suggest a vertebral anomaly, but there are other clinical and roentgenographic findings which should alert the examiner to such a possibility. Children with cutaneous abnormalities in the region of the back-dermal sinuses, hairy patches, dimples and hemangiomashould be carefully evaluated for the presence of associated anomalies of the cervical spine (Klippel-Feil), bony torticollis, congenital heart-disease ( 15 per cent), and Sprengel's deformity ${ }^{8}$. Children with congenital problems of the lower extremities, foot deformities, and particularly asymmetrical findings such as atrophy and hemihypertrophy, should be suspected of having an underlying vertebral deformity.

The young child with congenital

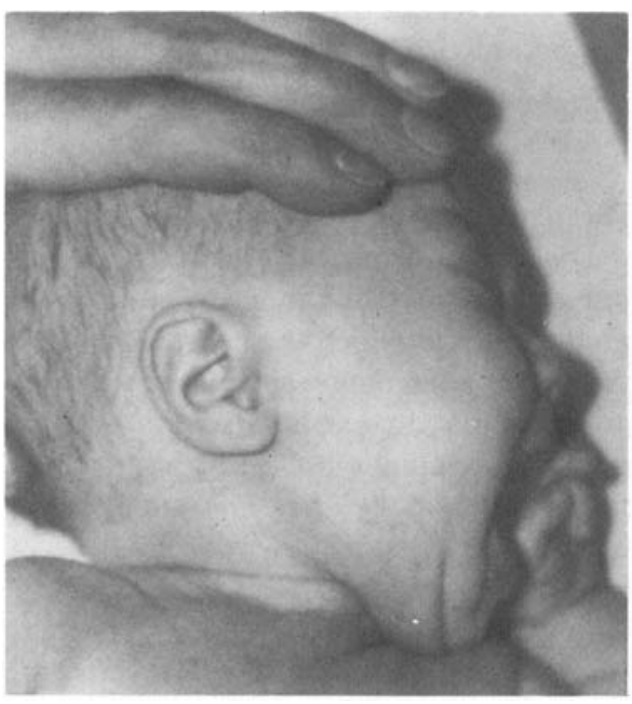

Fig. 1. Six-week-old infant with swelling in region of sternocleidomastoid muscle.

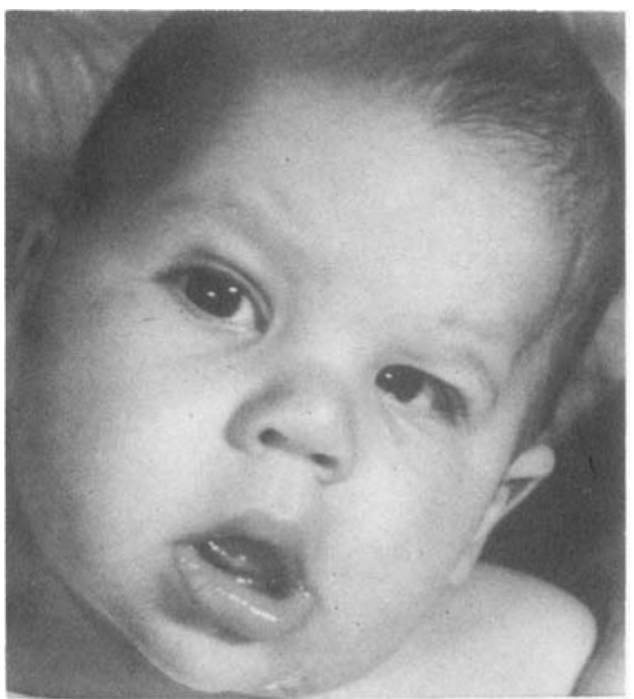

Fig. 2. Six-month-old infant with right-sided congenital muscular torticollis, Note rotation of skull, asymmetry and flattening of face, depression adjacent to left eye (on side of contracted sternocleidomastoid muscle). 
scoliosis will seldom have a neurological problem, unless there is associated diastematomyelia, myelodysplasia or sacral agenesis. Affected children have a 20 per cent incidence of associated anomalies of the kidney and bladder, which may only be discovered on intravenous pyelography ${ }^{9}$. This study should be routine for all children who have vertebral anomalies (Fig. 3b).

\section{Diastematomyelia}

Diastematomyelia is an uncommon congenital disturbance of vertebral architecture in which the neural elements, the spinal cord or intraspinal nerve-roots are split into two columns by a midline mass in the spinal canal, fixed anteriorly to the vertebral body. The mass may be an osseous or cartilaginous spicule of a fibrous septum partially or completely dividing the neural canal. Diastematomyelia may be localized at one vertebral level or extended over several segments, and is commonly found in the lumbar

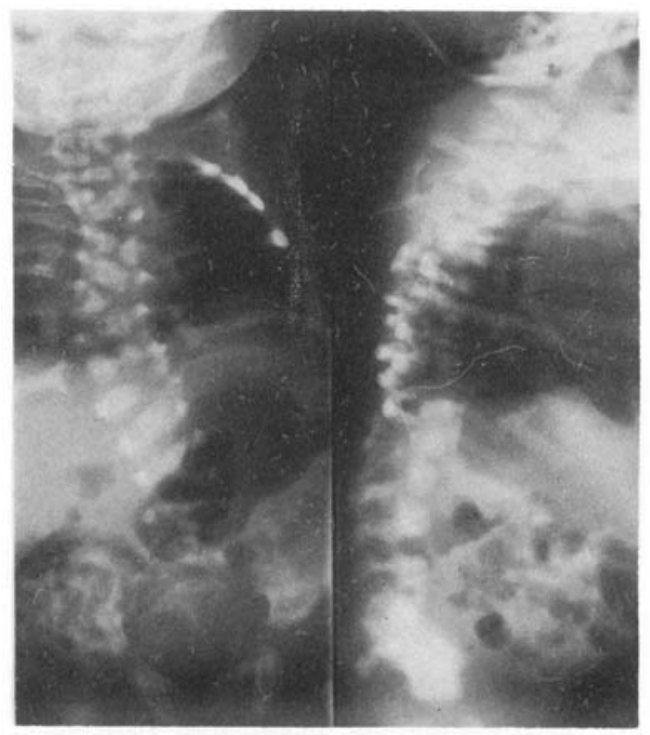

Fig. 3a. Newborn with multiple congenital anomalies of the spine. Routine roentgenography should include (left) antero-posterior and (right) lateral views of spine. region $^{10-12}$. It is presumed that the clinical consequences are due to the 'tethering' effect of the diastematomyelia on the normal ascent of the spinal cord. The diastematomyelia may act as a 'check-rein' on the upward migration of the neural elements, with progressive neurological signs in the lower extremities. It should be emphasized that the greatest change in the vertebral architecture occurs in the last six months of intra-uterine skeletal growth: differential growth during childhood is at a slower pace, with more time for adaptive changes in the spinal cord and nerve roots $^{13,14}$.

The majority of patients have a cutaneous abnormality in the midline of the back ${ }^{10,15-17}$ which can be an important clue to the diagnosis. The form of the cutaneous defect is extremely varied: a patch of hair, a discreet dimple, subcutaneous fatty tumor, pigmented nevi, and hemangiomas have all been reported $^{16-19}$. Although infrequent, the association of a dermal sinus is of

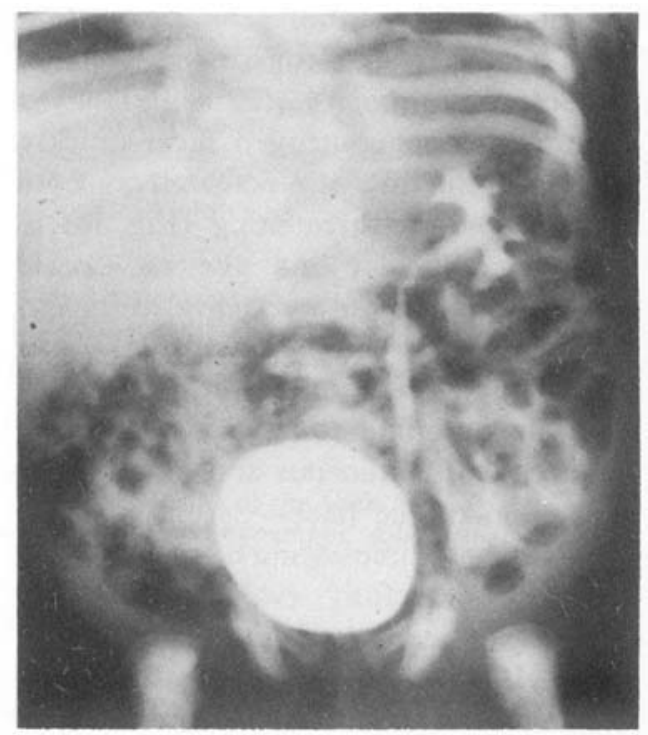

Fig. 3b. Same infant as in Fig. 3a. Intravenous pyelogram demonstrates absent right kidney. 
particular concern and must be carefully searched for, as it may represent a portal for entry of bacteria into the spinal canal ${ }^{20}$. The orifice may be quite small and innocuous in appearance, yet lead to abscess formation and meningitis, or a frank neural cutaneous fistula ${ }^{20}$. Similarly, the incidental discovery of such a defect should make one suspect diastematomyelia ${ }^{16}$.

\section{Fractures in neonates}

The majority of fractures occur at the -time of delivery and aire either epiphyseal separations of the humerus or femur, or midshaft fractures of the long bones, most commonly the clavicle ${ }^{21,22}$. The few studies reported in recent times suggest that the over-all incidence of fracture is uncommon, occurring in less than 1 per cent of newborn infants ${ }^{21}$. The vast majority are clavicular fractures, of which only a small percentage are recognized ${ }^{21}$. Similarly, many epiphyseal separations are only slightly displaced and may be undetected ${ }^{22}$. In contrast, midshaft fractures of the long bones generally are recognized immediately, often by the obstetrician at the precise moment they occur $^{23,24}$.

As might be expected, injury to a bone or joint occurs more often with complicated obstetrical procedures or breech deliveries ( 6 per cent), and is rare in spontaneous labor $^{21,25}$. Injury is more common among first-born infants, but with the exception of the clavicular injuries, the mothers seldom have a narrow pelvis, and relatively few (14. per cent) of the children are premature $^{21,22,25}$.

Clinically the child has a tender, swollen extremity, often noted the day following delivery ${ }^{22,25}$. The fractured extremity hangs limply and the child avoids voluntary movement of the $\operatorname{limb}$ (pseudoparalysis) $^{22}$. Swelling is usually extensive, the soft tissues are tense, the skin erythematous, and the child may have lowgrade fever ${ }^{22}$. The clinical and radiographic appearance is similar to bone or joint infection, and the two problems are often confused, particularly in the child with an epiphyseal separation.

\section{Cervical spine injuries in neonates}

The most commonly reported spine injuries in the neonatal period are those that involve the cervical spinal cord. Cervical injury appears to be uncommon, or at least not commonly recognized, and occurs principally in two areasproximally near the occiput (the $\mathrm{C} 1-2$ articulation) and distally near. the thorax (C6-7 or $\mathrm{C} 7-\mathrm{T} 1)^{22}$. However, there is seldom roentgenographic evidence of a bony injury ${ }^{26,27}$. The neonatal spine is more elastic than the spinal cord itself: Towbin noted that traction could lengthen the newborn spine by two inches, but the spinal cord by only one-quarter inch ${ }^{28}$. Thus, stretching forces can cause a complete transection of the spinal cord without roentgenographic evidence of bony disruption.

Studies of stillborn infants demonstrate that the maximum angulation of the vertebral column occurs at the cervicothoracic junction, but without vertebral disruption. Consequently, if a dislocation or fracture of the cervical vertebrae is discovered, it suggests a severe transection-type injury to the spinal cord ${ }^{22}$. $\mathrm{Cl}-2$ injuries are more common following cephalic delivery, and are believed due to excessive rotational forces, whereas the C6-Tl injury more often follows excessive traction in a breech delivery ${ }^{22,26}$.

Following a spinal-cord injury, the infant typically exhibits a period of 'spinal shock'-hyporeflexia, hypotonia, respiratory distress and decreased ventilation. Often there is Erb's palsy ${ }^{26,29}$ or injury to the phrenic nerve, with paralysis of the diaphragm. Later, if the 
external muscles of respiration remain paralysed, the child will develop a bellshaped chest ${ }^{27}$. With time there will be a gradual onset of hyperreflexia, typically most prominent in the lower extremities. Previously many infants died shortly after the injury occurred, but more recent technological advances have improved the survival rate. If a myelogram is performed shortly after the injury, it usually demonstrates a block in the subarachnoid space as a result of hemorrhage. Later, localized cord atrophy may be identified ${ }^{27}$.

The fracture usually occurs through the epiphyseal plate of the vertebral body $22,26,30,31$. Simple positioning in extension usually achieves reduction of the bony elements and the fracture heals rapidly ${ }^{32,33}$. The large problems, of course, is the continuing neurological injury. Laminectomy and decompression have not been particularly helpful ${ }^{27}$.

The flying fetus. This is an unusual syndrome, frequently associated with cervical spinal-cord injury. The distinguishing feature is the intra-uterine position of marked hyperextension of the cervical spine. The position has been variously described as the 'flying fetus', 'star-gazing fetus' or 'opisthotonus ${ }^{\text {'33-35. }}$ The hyperextension is so marked that the occiput may be at the level of the 11 th thoracic vertebra ${ }^{36}$. This intra-uterine posture appears to make the neck more sensitive to longitudinal stretching and flexion $^{36}$, and more susceptible to spinalcord injury and avulsion of the cervical roots $^{36,37}$. Approximately 70 cases have been reported in the literature, and 75 per cent of the injuries occur during breech presentation ${ }^{35,36}$. Current estimates are that 25 per cent of children with this unusual posture, delivered vaginally, will have significant cord injury ${ }^{35}$. However, spinal-cord injury has been reported only once among children with the same posture delivered by cesarean section ${ }^{35,38}$.
Interestingly, this unusual hyperextension posture may persist for one to two months after delivery ${ }^{36}$.

Occult cervical injuries. Autopsy studies of newborns dying within the first week of life suggest that the incidence of spinal injury is more common than is clinically appreciated $^{39}$. Routine autopsies of newborn deaths indicate only a 1 per cent incidence of spinal-cord damage, whereas autopsies done specifically to search for this problem suggest a much higher incidence of 10 to 33 per cent ${ }^{40}$. Yates, who autopsied 60 children dying about the time of birth, found evidence of distortion or trauma to the cervical spine in 27 cases. These findings included hemorrhage in joint capsules, torn ligaments and dura, and extensive bruising of the spinal cord and nerves. Complete destruction of the spinal cord was uncommon $^{41}$. In a similar series, Jones found 30 per cent with evidence of distortional trauma to the cervical spine-extra- and subdural hemorrhage, and hemorrhage in the spinal cord, nerve root and ganglia ${ }^{42}$. Several infants showed evidence of birth trauma to one or both vertebral arteries, including tearing of the branches of the vertebral artery at the junction of the main trunk ${ }^{40-42}$.

Although circumstantial, the evidence suggests a significant incidence of unrecognized (occult) cervical trauma in infants who survive. The spectrum of clinical findings range from mild respiratory depression at birth to complete areflexia and hypotonia. In the majority of cases roentgenograms will appear normal. Allen ${ }^{44}$, who reviewed 31 children initially classified as having infantile spinal muscular atrophy (Werdnig-Hoffmann disease) or amyotonia congenita, reported that 58 per cent had a clinically nonprogressive, non-familial, neurological disorder, which could have been due to spinal-cord trauma at the time of birth ${ }^{44}$ 
(Fig. 4). This suggests that a number of minor cervical injuries result in direct contusions or ischemia to the brainstem and spinal cord, but not death, and may account for some children with the diagnosis of cerebral palsy' or the 'more clumsy' child ${ }^{40-42,44,45}$

\section{Nerve injuries}

\section{Brachial-plexus injury in the newborn}

This injury is the result of traction on the brachial plexus during delivery. The usual mechanism is distraction of the upper extremity away from the head and neck, and stretching the nerve roots as they exit from the cervical spine. Usually the delivery is difficult, and the infants are large ${ }^{46,47}$. Many affected infants are the offspring of a diabetic or pre-diabetic mother, which to some degree may account for the large size and difficult delivery ${ }^{47}$. Kuhns and associates discovered that these children also have unusual distribution of fat, with more fat over the shoulders than normal infants ${ }^{47}$. As a consequence, the biacromial distance (the distance across the shoulders) is larger than the diameter of the head. During a cephalic delivery, following presentation of the head, shoulder dystocia may develop, with inadvertent traction injury to the brachial plexus. This is supported clinically by the fact that the majority of brachial-plexus injuries occur as a result of shoulder dystocia during a vertex delivery.

In a breech presentation, the problem is more likely to be due to cephalopelvic disproportion of the after-coming head ${ }^{47}$. In the report by Kuhns and colleagues, only 12 per cent of the mothers had cephalo-pelvic disproportion, and only 14 per cent of the infants were breech ${ }^{47}$. There were as many multigravid mothers as primiparous, and the deliveries were prolonged or traumatic, with traction the usual mechanism of injury.

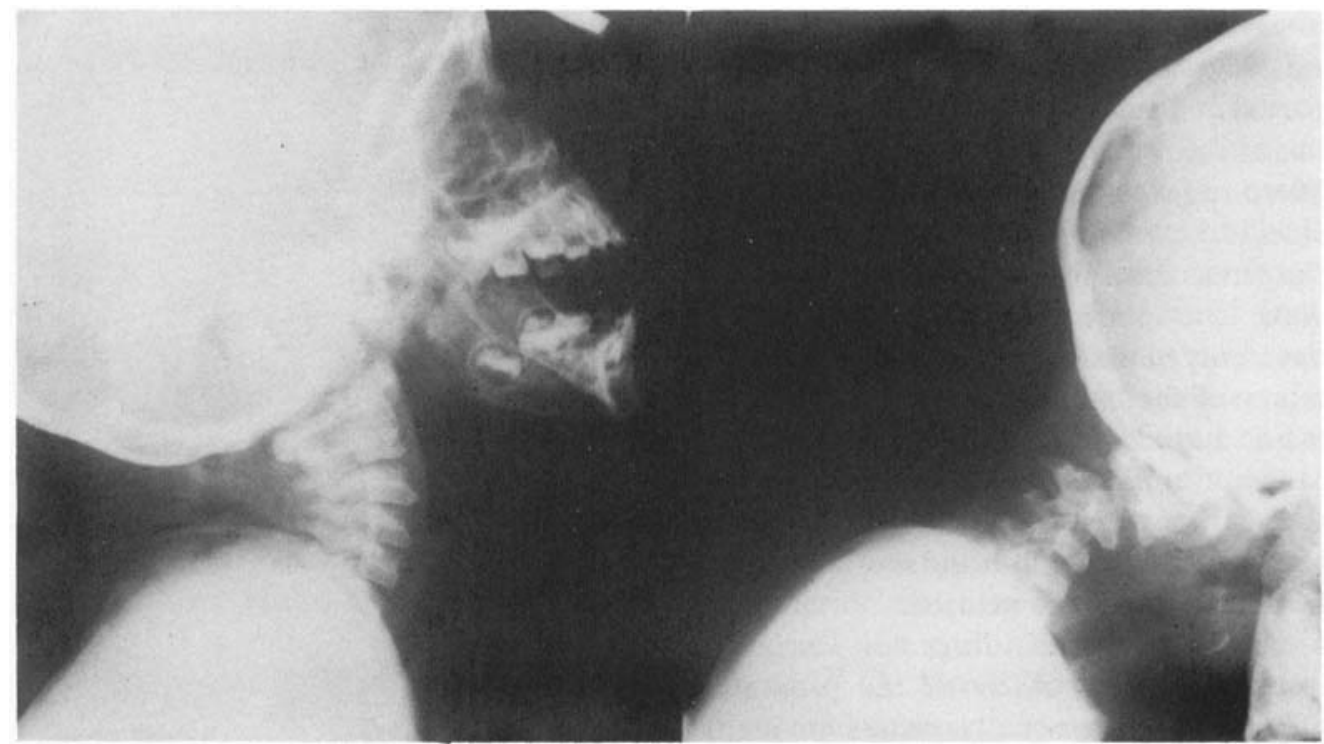

Fig. 4. Lateral flexion-extension views of cervical spine of 18-month-old child, demonstrating marked instability of C2-3 interspace. Child required respiratory support after delivery, was areflexic and was treated as a floppy infant. Subsequently diagnosed as congenital hypotonia, with slow acquisition of motor milestones. Instability first noted at 16 months, as incidental finding on lateral views of chest following bout of pneumonia. Initial cervical injury suspected to have occurred at time of delivery, but no recognized. 
Improvement in obstetric care has reduced the incidence during this century from $1 \cdot 56$ to 0.38 per thousand live births, but there has been no significant change over the last decade ${ }^{48}$.

The injury is divided into three types: (1) Erb's Palsy, the C5-6 lesion (Erb's point, the junction of the nerve roots of C5-6, before the supraclavicular nerve emerges), with denervation of the deltoid, supraspinatus, biceps and brachioradialis; (2) Déjérine-Klumpke paralysis, C8-T1 lesion, denervation of the intrinisic muscles of the hand, flexors of the wrist and fingers (intrinsic minus claw-hand), and sympathetic muscles (Horner's syndrome), typically associated with hyperabduction of the shoulder and arm; (3) Erb-Duchenne-Klumpke, or a combined lesion involving the entire arm. Paralysis of the diaphragm may be expected when the injury is high enough to involve the $\mathrm{C} 4$ nerve root.

The infant holds the arm loosely at the side of the thorax; the entire arm is internally rotated at the shoulder, with extension of the elbow, pronation of the forearm and flexion at the wrist ('headwaiter's tip' position) (Fig. 5). The Moro relfex is diminished on the involved side. If the lesion is the Tl (Klumpke) type, the wrist and finger flexors are involved, with an intrinsic minus claw-hand deformity. Swelling may be found in the region of the shoulder and supraclavicular fossa. Initially there will be full passive range of motion, but no active motion in the denervated areas. Local pain and tenderness are common and are believed to be due to traumatic neuritis.

The differential diagnosis includes fracture of the clavicle or the proximal humerus, which usually results in pain, limitation of passive motion and crepitation. The appearance of the arm is similar to that in infants with arthrogryposis, but in the latter case passive motion of the joints will be limited, and both upper and lower extremities will be involved. Erb's palsy may be confused with an injury to the cervical spine, and the two may co-exist. Children with spinalcord trauma or cerebral palsy generally have ipsilateral upper and lower extremity involvement.

The primary goal in treating these infants is to avoid contractures of the involved joints by preserving a full range of passive motion ${ }^{48-50}$. The importance of maintaining normal joint motion must be emphasized to the parents. If neurological function returns, the reinnervated musculature will require supple joints; if it does not, prevention of contractures will allow a greater latitude in the choice of reconstructive procedures. Instructions

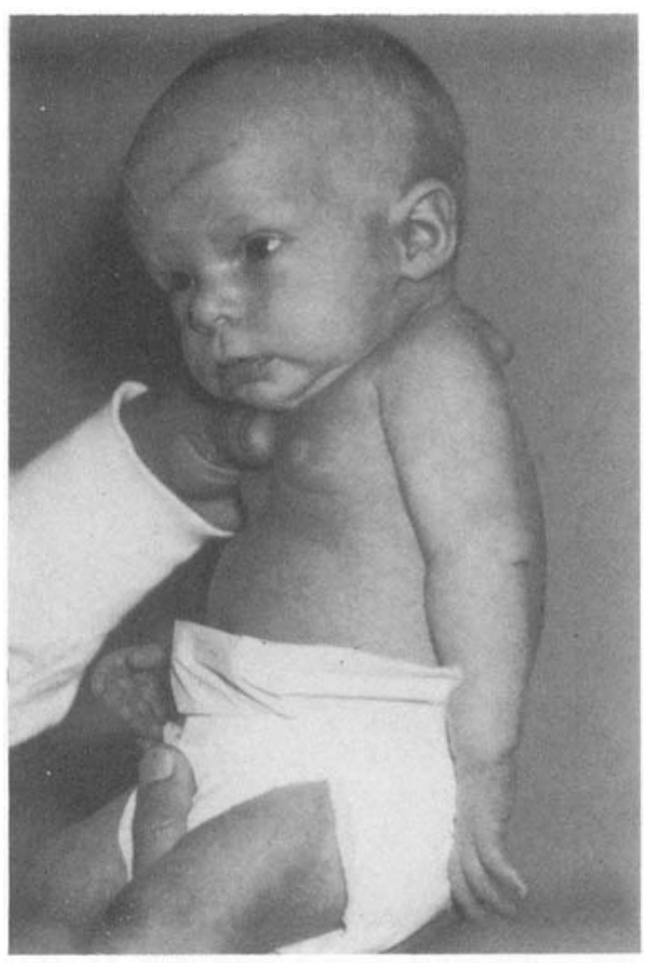

Fig. 5. Infant with Erb's type brachial plexus injury (C6). Arm is held loosely against thorax, internally rotated at shoulder, with elbow extended and wrist flexed. 
for exercises by a physical therapist and follow-up should be arranged before the infant is discharged from the nursery. Forceful manipulation should be avoided, and the practice of pinning the arm to the bed can lead to additional injury if the infant tugs with the relatively insensitive extremity. Judicious use of bracing, in concert with physical therapy, can be helpful.

Neurological recovery is usually achieved within the first six months, but may extend to 18 months ${ }^{46,48}$. However, less than 20 per cent achieve full neurological recovery ${ }^{46}$. Reconstructive procedures are considered when the older child, prior to school age, is able to cooperate in an accurate assessment of remaining muscle function ${ }^{51}$. Direct surgical repair of a lesion has not been fruitful ${ }^{49}$.

\section{Sciatic nerve injuries}

Sciatic nerve injury occurs from one of three mechanisms:

(1) Directly, by intramuscular injection of medication near the nerve. This complication is now less frequent because the hazard has been recognized and injection techniques have been altered ${ }^{52,53}$;

(2) Indirectly, by parenteral administration of agents through the umbilical vessels, particularly the umbilical artery ${ }^{54,55}$;

(3) Traction on the nerve during closed or open reduction of congenital dislocation of the hip.

In the direct injury, the common peroneal nerve is more frequently affected since it is superficial and more lateral in location. However, both divisions may be involved $^{52}$. Typically there is immediate loss of motor and sensory function of the nerve, with both local and referred pain ${ }^{52}$. The child is unable to actively dorsiflex (foot drop) and evert the foot ${ }^{54}$. There is also anesthesia of the foot and the lateral aspect of the leg. The site of injection is tender locally and a firm mass (granuloma) may be palpable in the buttock ${ }^{52}$. Recovery may occur any time between six weeks and 18 months later, but in some cases may take as long as three years. Only one-third recover completely ${ }^{52}$, but active dorsiflexion occurs to a functional degree in the majority of children ${ }^{53}$.

Indirect injury to the sciatic nerve is the result of thrombosis of the inferior gluteal artery after injection of sclerosing or irritative drugs into the umbilical $\operatorname{artery}^{54,55}$. At birth, material injected into the umbilical artery will pass down the internal iliac artery (usually the left) where it enters the inferior gluteal or superior gluteal artery. Before birth the former is the largest branch of the internal iliac artery and constitutes the main arterial blood-supply for the lower limbs and sciatic nerve ${ }^{54}$. The children are usually debilitated and hypotensive at the time of the injury, so the material can travel further retrograde than if the systemic pressure were higher.

Often there is a firm, non-mobile mass in the left upper buttock, consisting of fat necrosis and early calcification ${ }^{54}$. There is marked hypervascularity and adhesions about the nerve and neighboring structures. Circulatory changes may be evident in the skin of the limb or buttock, or less commonly, the abdominal wall. Purple, mottled discolorations are seen over the affected parts, with induration, ulceration and sloughing of the skin; and in some cases thrombosis of the common iliac artery can result in loss of the entire lower extremity from mid-thigh. Thrombosis of the inferior mesenteric vessels can lead to gangrene and perforation of the sigmoid colon $^{23,54-56}$. Nerve involvement varies from mild paresis to complete flaccidity ${ }^{56}$. The chance of recovery is good if the paralysis is incomplete or if improvement occurs within a few days, but such improvement is rare. 


\section{Gangrene of the newborn}

This is an uncommon condition, usually resulting from decreased perfusion to a portion of an extremity. In approximately one-half of affected infants the condition develops within the first day of life $\mathrm{e}^{24,57,58}$. A variety of situations can result in this conditions $^{59}$, but the end result is diminished perfusion and local ischemia (Fig. 6). Knowing the exact sequence of events that led to the insult is helpful in determining the etiology, and consequently the treatment. The lesion usually involves the extremities, and orthopedic consultation is often required in the acute and reconstructive management of these children.

It is important to distinguish gangrene of the newborn from necrotizing fasciitis of the newborn, a much more virulent condition in which there is rapidly developing sepsis and destruction of tissue $^{60}$. The latter condition is associated with a high mortality rate and demands an entirely different course of treatment from that for gangrene of the newborn, including prompt and vigorous supportive measures and surgical debridement ${ }^{60}$.

Gangrene of the newborn seems to be more common in pregnancies associated with spontaneous rupture of the amniotic sac, particularly if there is a delay in delivery or a long, difficult, dry labor ${ }^{57}$. In these situations the extremity may prolapse between the presenting head and the maternal pelvis in the birth canal. If trapped thus, a groove in the extremity and cyanosis of the extremity may be noted at birth, indicative of construction in the birth canal and obstruction rof venous return. Maternal diabetes may also increase the infant's susceptibility to venous occlusion, as there is an increased risk of venous thrombosis in newborn offspring of diabetic mothers ${ }^{52}$. Valderrama and associates reported a case of gangrene of the newborn associated with maternal diabetes ${ }^{6 !}$; the infant was born with an edematous hand which gradually became cyanotic and eventually gangrenous.

A gangrenous region may occur as the result of direct arterial injury, or the artery may be compromised by a relative occlusion and an accompanying hypotensive episode. The differential diagnosis is long and includes sepsis, congenital heart-disease, birth trauma, emboli from a closing patent ductus, extension of a thrombus from the umbilical arteries, and various diseases involving the arterial wall ${ }^{24,57,62-65}$. Polycythemia and vascular coagulopathies have been incriminated on occasion, as has dehydration associated with severe illness ${ }^{58,66}$. Other causes include direct trauma to a vessel during attempted venipuncture or catheterization, resulting in spasm or thrombosis, or catheterization of the umbilical artery ${ }^{67}$. Cartwright and Schreiner ${ }^{68}$ reported an infant who lost four fingers and part of a thumb as the result of percutaneous radial-artery catherization. Ischemia occurred 48 hours after insertion of the catheter, following a severe bout of hypoxia and hypotension.

Ischemic signs are usually present immediately following the injury and subsequently there is cyanosis and paralysis. Usually there are no pulses distal to the injury, and the part is pale and cold. In approximately two-thirds of affected children, a single major vessel in the extremity appears to have been involved. Subcutaneous infiltration of intravenous medication may lead to a similar but more localized reaction, with blistering and sloughing of the skin (Fig. 7).

Initial treatment is supportive, and includes adequate hydration, maintenance of an aseptic environment for the extremity, preventing infection or controlling it if it occurs, and surgical drainage if an abscess develops ${ }^{57}$. As a 
general rule, it is better to let the area become gangrenous and demarcate rather than make an early debridement: usually this results in a considerably smaller loss than first anticipated. If the artery is of sufficient size and the problem is recognized quickly, embolectomy or thrombectomy may be considered; they have been successful in large vessels ${ }^{24}$.

\section{Congenital annular bands}

Congenital annular constricting bands in the extremities are rare, but are regularly accompanied by other orthopaedic anomalies, including congenital amputation (Fig. 8), distal syndactyly and club-foot. Torpin reported on the dissection of 14 placentae and documented the amniotic bands in these patients ${ }^{69-71}$. Despite these and numerous other papers which reported delivery of the amputated parts along with the fetus, other

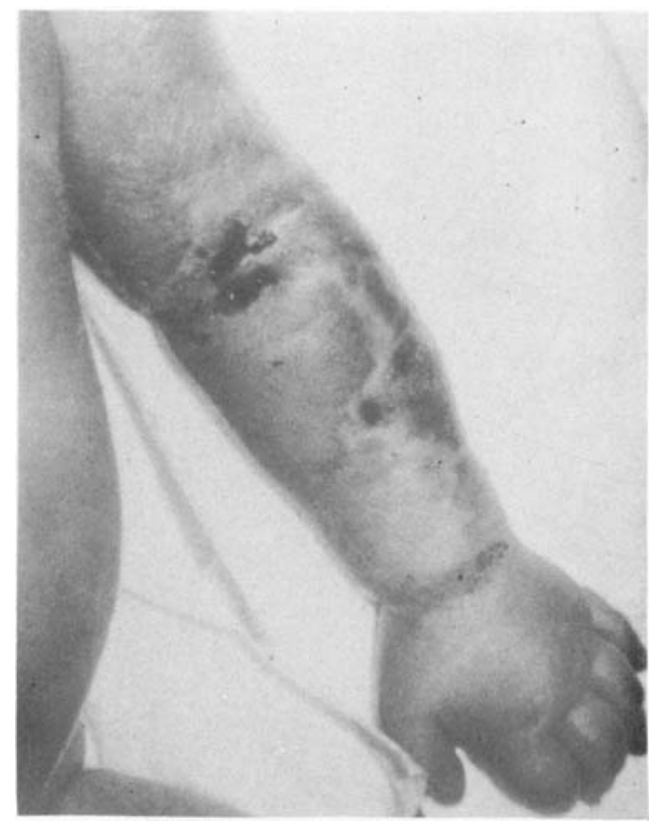

Fig. 6. One-day-old child with gangrene of the newborn, demonstrated by skin changes on extensor surface of forearm. authors $^{72.73}$, particularly Streeter ${ }^{74}$, have attempted to show that these congenital amputations and bands are secondary to focal dysplasia of the fetus. Streeter's theory on focal deficiency of fetal tissue continues to be accepted today by many, despite all evidence to the contrary.

Torpin notes that while the amnion may rupture, the chorion may remain intact with resultant loss of amniotic fluid, without complication to the pregnancy ${ }^{70}$. Following this amniotic rupture, which may be secondary to trauma early in pregnancy, the amnion may form freefloating strings which may encircle extremities, the cord, or even the neck ${ }^{75}$. More than half of the mothers had a poor obstetric history or some form of difficulty during pregnancy-i.e. rupture of the membrances with leaking fluid or blood early in the pregnancy, premature delivery, history of strangulation of a twin, or a

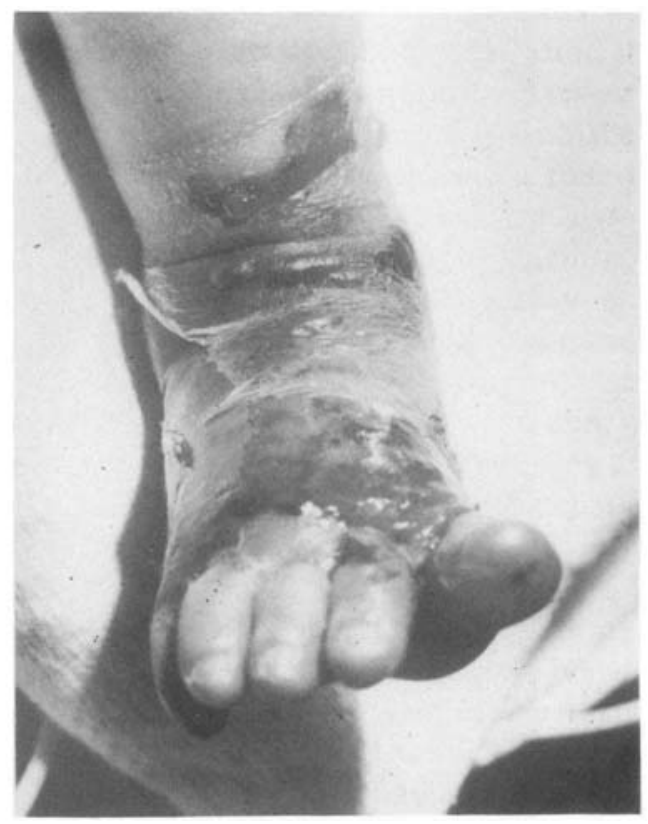

Fig. 7. Sloughing of skin on dorsum of foot, secondary to inadvertent subcutaneous infiltration during intravenous administration of antibiotics. 


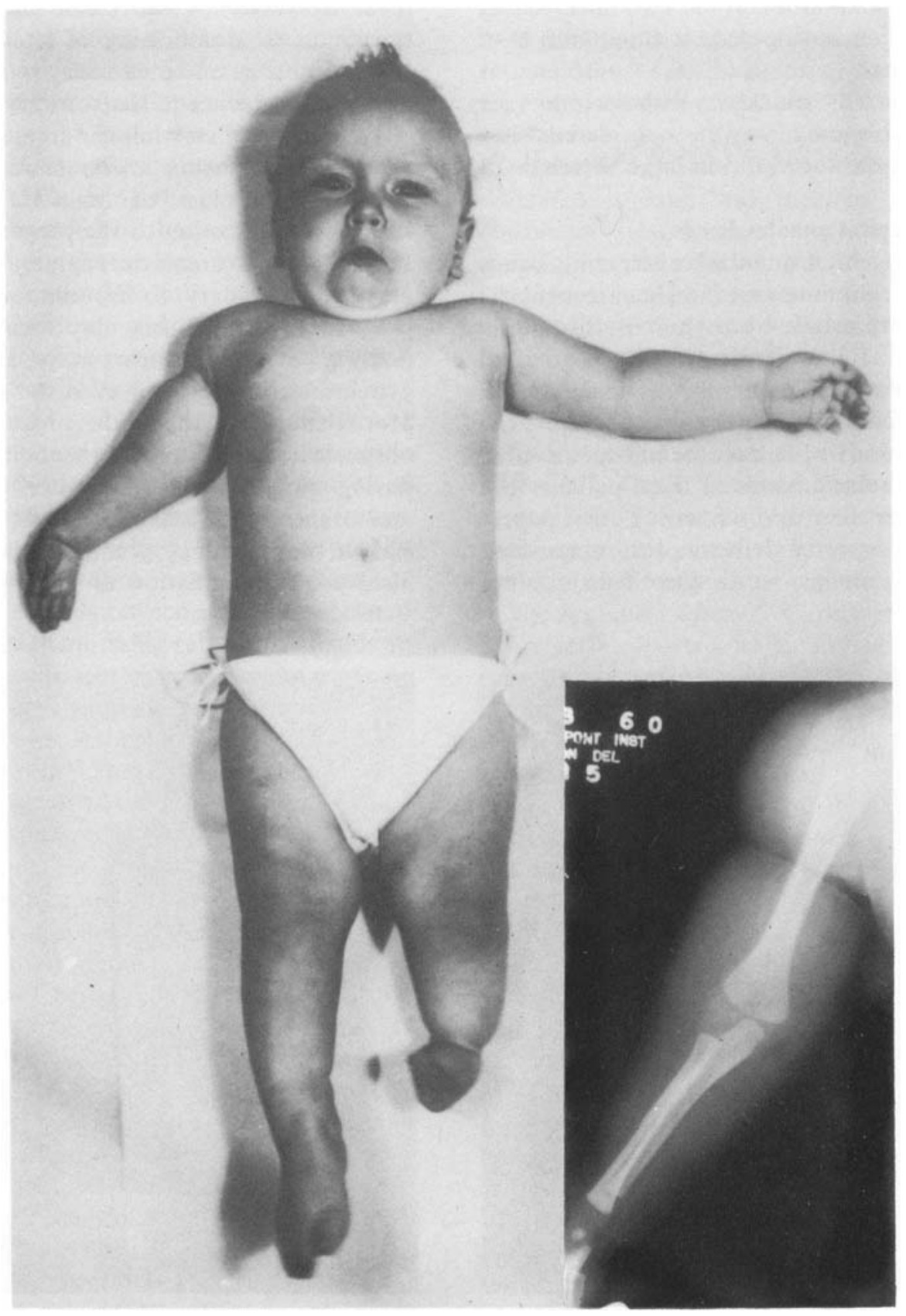

Fig. 8. Infant with multiple congenital annular bands. Clinical appearance of bands in mid-portion of right arm and distal portions of both legs. Inset: Roentgenographic appearance of upper right-arm, showing presence of band but no bone changes. Eventually, amputation was required of right hand and left foot. 
history of miscarriage ${ }^{76}$. The band may extend through the fascia and as far as bone. Depending on the depth of the band, there may be edema and enlargment of the distal portion, and some fetuses undergo auto-amputation in utero (Fig. 9).

Amputation of fingers and toes is relatively common, but an entire upper or lower extremity may be amputated. It is not unusual to have bilateral loss. Syndactyly of the fingers is common: the appearance is as though the fingers have been tied together at their tips (acrosyndactyly), with an open space between the fingers proximal to the distal syndactyly. There may be an amputation of an adjacent digit at the same level. Clubbing of the feet occurs in approximately 50 per cent of these children, and may be bilateral ${ }^{76}$.

Shallow grooves seldom require either immediate or later treatment. Early release of the band may be required for the infant who has a distal lymph obstruction or neurovascular complications because of a deep band ${ }^{76}$, and is recommended even for small digits, rather than allowing the part to go on to amputation. Excision of the

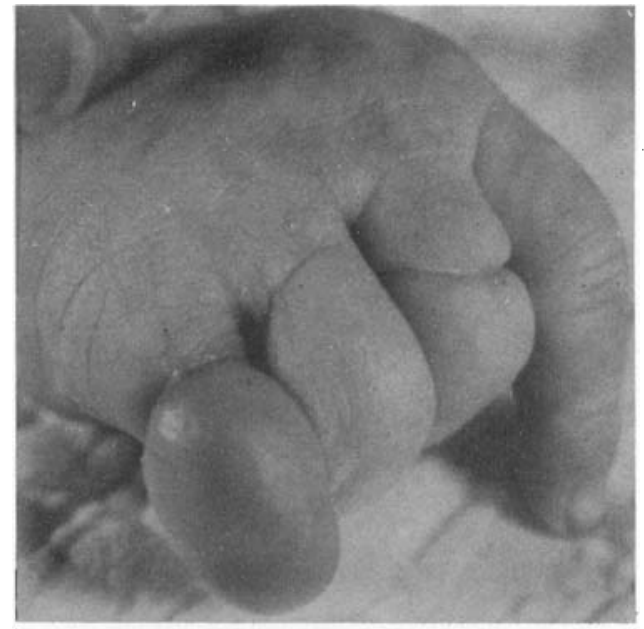

Fig. 9. Congenital annular band of fifth finger. Portion distal to band is edematous and swollen. Note less severe bands on long and ring fingers. band must be performed down to and including the fascia, and back to normal skin on either side ${ }^{76}$. Surgical correction of distal syndactyly is indicated in early childhood to improve function of the digits and to prevent deformity with growth. Treatment of associated club-foot should be begun immediately after birth, in the same manner as described in the section on club-foot.

\section{Infection}

Neonatal and infantile hematogenous osteomyelitis and septic arthritis differ from those of the older child on the basis of the bacterial agents and anatomical factors, and especially of clinical findings and presentation of the illness. However, the diagnostic methods, treatment and complications of the bone and joint infections are similar to those in the older child.

\section{Clinical signs}

Acute hematogenous osteomyelitis in the neonate may have only a few clinical symptoms. The fever, vomiting and severe systematic symptoms associated with the disorder in older children are rarely found in the neonate and infant. Local signs are the predominant finding: warmth, swelling, pain, and tenderness may be present when specifically sought, but more frquently the presenting problem is unwillingness to use an extremity (pseudoparalysis of infancy). Osteomyelitis is a potential sequel to neonatal and infantile sepsis of any etiology.

Compared with older children, there are certain anatomical differences in the bones of the newborn which may make their susceptibility and response to infection dissimilar. In the older child the growth plate forms a thick avascular barrier infection, preventing direct spread ' the metaphysis to a neighboring joir. 
the newborn, however, the growth plate is thin, less adherent, and may allow metaphyseal osteomyelitis to spread via transepiphyseal vessels through the thin plate into the epiphysis ${ }^{77,78}$. These vessels are not present in the older child. Infection may also erode through the thin cortex of the metaphysis, and spread under the periosteum and into the joint. These two anatomical features make septic arthritis a frequent accompaniment to metaphyseal osteomyelitis, especially in the neonate (Fig. 10). The ease with which infection spreads into the joint and growth plate in the very young leads more frequently to permanent epiphyseal damage, which is rare in the older child.

The clinical features of septic arthritis are variable, but fever and irritability are more common than in metaphyseal osteomyelitis. Clinical findings of a warm, swollen, irritable joint require urgent management if joint function is to be preserved.

Septic arthritis in the neonate commonly involves the hip joint, and the clinical findings may make it difficult to differentiate septic arthritis from hip

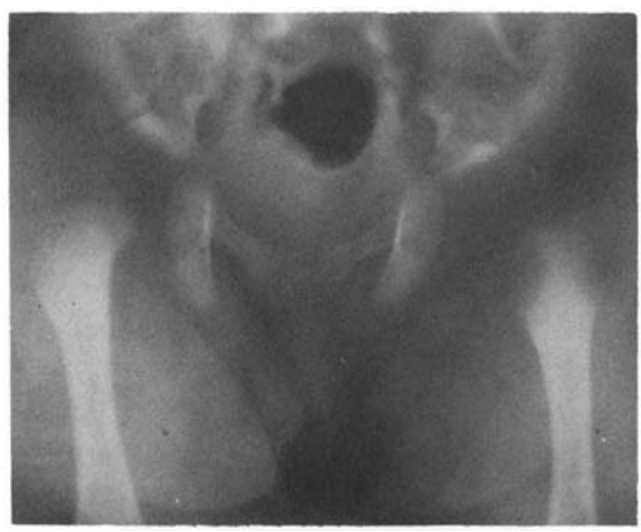

Fig. 10. Roentograph of pelvis and hip of threeweek-old with one-week history of irritability of left leg during diaper changes. Note metaphyseal latency in left proximal femur and increased cartilage space between acetabulum and proximal femur, suggesting metaphyseal osteomyelitis and septic dislocation of left hip. fracture or dislocation. The earliest sign may be irritability, demonstrated only during diaper changes. The child may appear normal and have no fever or change in appetite, but be unwilling to move the entire lower extremity (pseudoparalysis), the most comfortable position being flexion and adduction. Local warmth and swelling are difficult to identify, but hip irritability is not. The hip may be dislocated as a result of inflammation and purulent material in the joint (Fig. 11). The neonate's somewhat lethargic systemic response is especially seen in streptococal infections, which may have a chronic and indolent course and involve multiple bones by the time the infection is recognised.

\section{Diagnosis}

In osteomyelitis the white blood-cell count may be normal or depressed, whereas the erthrocyte sedimentation rate is almost always elevated. Staphylococcus aureus is still the most common organism isolated from young patients with osteomyelitis $^{79-81}$, although streptococcal infection is becoming more common.

Septic arthritis is a common accompaniment of osteomyelitis, especially in the neonate. As with osteomyelitis, septic arthritis must be treated with appropriate intravenous antibiotics, and usually by surgical drainage. The common etiological agents are the same as in osteomyelitis (staphylococcus and streptococcus).

\section{Treatment}

In suspected osteomyelitis, if needle aspiration produces purulent material from beneath the periosteum or bacteria are seen on gram stain, the area should be surgically drained. Staphylococcus aureus is especially chondrolytic and prompt drainage may preserve joint function. In the rare instances the diagnosis may be made early in the course of infection, with 
only tenderness, soft-tissue swelling and cellulitis as indications. In this occasional instance, antibiotics should be begun after taking appropriate cultures, reserving surgery for those who do not respond to drug therapy.

Management of septic arthritis is the same at all ages. Needle aspiration (with fluoroscopy available to document that the joint was entered if no fluid is obtained) is followed by surgical drainage if purulent material is produced.

Antıbiotic treatment should include coverage for penicillin-resistant staphylococcus and streptococcus. Any known perinatal problem relative to the mother may provide a clue as to the bacterial agent and guide antibiotic selection for the neonate. Intravenous therapy is the most reliable, and oral therapy probably should not be used early in treatment unless it is possible to closely monitor blood levels of antibiotics. Intravenous antibiotic therapy should be continued until the sedimentation rate returns to normal-usually three to six weeks. Immobilization of the affected limb is an integral part of treatment, both to provide comfort for the child and to prevent contractures and deformity. It need be continued only until the child is able to move the limb comfortably.

\section{Conclusions}

Orthopedist participation in the care of the infant should begin as soon as a deformity or the potential for deformity is recognized. Early diagnosis in the newborn
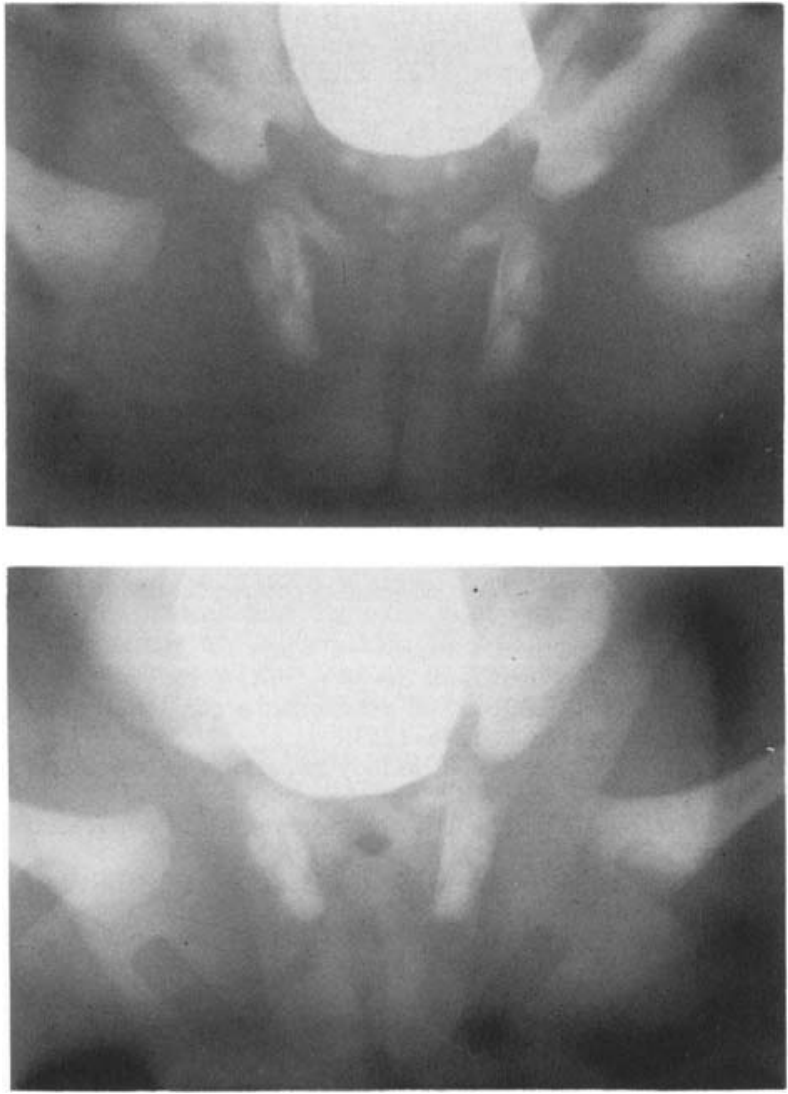

Fig. 11. Roentgenogram of twoday-old infant with clinically dislocated hip Upper: distance between metaphysis of left proximal femur and acetabulum is increased, consistent with congenital dislocation of hip. Hip did not reduce in Pavlik harness and while in harness the child was extremely irritable, arousing suspicion of infection. Subsequent roentgenograms revealed osteomyelitis of left ilium, and hip was dislocated secondary to sympathetic effusion in joint. Lower: Reduced position of hip after treatment of infection. 
period can lead to early treatment and improved results. However, it is the pediatrician who first sees the baby and must initiate the referral; therefore he must be alert to the early recognition of musculoskeletal problems. The neonatal period is a unique time in the child's life for the treatment of many musculosketetal problems. It is a time of rapid proliferation of the cells of the bones and joints, which must be harnessed if normal growth and function is to be achieved. If ignored and lost, these same forces can irreparably deform the bones and joints.

The orthopaedist can also play a significant and active rôle in the education of the family regarding the impact of the child's deformity, both now and in the future. For neonates with multiple anomalies, such as myelodysplasia or sacral agenesis, several specialists may be involved in the child's management, and the future rôle of the orthopaedist will need to be explained to the family.
Early diagnosis and appropriate management of most infantile orthopaedic problems can simplify and abbreviate the treatment required, although the majority of children will require observation for all of their growing years. Ultimately, orthopaedic management should be aimed at preventing deformity and musculoskeletal disease: initiating care in the perinatal period is but a step in that direction.

Acknowledgement: Much of the material in-this paper appears in a recent book by Dr. Hensinger and Dr. Jones, Neonatal Orthopedics, published by Grune and Stratton, New York, and we are grateful to the publishers for their permission to publish the material here.

\section{AUTHORS' APPOINTMENTS}

Robert N. Hensinger, M.D., Professor of Orthopaedic Surgery, University of Michigan, University Hospital, Ann Arbor, Michigan.

Eric T. Jones, M.D., Ph.D., Associate Professor, Department of Orthopaedic Surgery, West Virginia University, Morgantown, West Virginia.

\section{REFERENCES}

1. Lind, C. M., Low, Y. S. (1972) 'Sternomastoid tumor and muscular torticollis.' Clinical Orthopedics and Related Research. 86, 144-150.

2. Coventry, M. B., Harris, L. E. (1959) 'Congenital muscular torticollis in infancy. Some observations regarding treatment.' Journal of Bone and Joint Surgery, 41A, 815-822.

3. McDonald, D. (1969) 'Sternomastoid tumor in muscular torticollis.' Journal of Bone and Joint Surgery, 51B, 432-443.

4. Staheli, L. T. (1971) 'Muscular torticollis: late results of operative treatment.' Surgery, 69, 469-473.

5. Brooks, B. (1922) 'Pathological changes in muscle as a result of disturbances of circulation.' Archives of Surgery, 5, 188-216.

6. Hummer, C. D., MacEwen, G. D. (1972) 'The coexistence of torticollis and congenital dislocation of the hip.' Journal of Bone and Joint Surgery, 54A, 1255-1256.

7. Winter, R. B., Moe, J. H., Eilers, V. E. (1968) 'Congenital scoliosis-a study of 234 patients, treated and untreated. I: Natural history.' Journal of Bone and Joint Surgery, 50A, 1-15.

8. Hensinger, R. N., Lang, J. R., MacEwen, G. D. (1974) 'Klippel-Feil syndrome: a constellation of associated anomalies.' Journal of Bone and Joint Surgery, 56A, 1246-1253.

9. MacEwen, G. D., Winter, F. B., Hardy, J. H. (1972) 'Evaluation of kidney anomalies in congenital scoliosis.' Journal of Bone and Joint Surgery, 54A, 1451-1454.

10. Winter, R. B., Haven, J. J., Moe, J. H., Lagaard, S. M. (1974) 'Diastematomyelia and congenital spine deformities.' Journal of Bone and Joint Surgery, 56A, 27-39.

11. Keim, H. A., Greene, A. F. (1973) 'Diastematomyelia and scoliosis.' Journal of Bone and Joint Surgery, $55 \mathrm{~A}, 1425-1435$.

12. Hilal, S. K., Marton, D., Pollack, E. (1974) 'Diastematomyelia in children. Radiographic study of 34 cases.' Radiology, 112, 609-621.

13. Barson, A. J. (1970) 'The vertebral level of termination of the spinal cord during normal and abnormal development.' Journal of Anatomy, 106, 489-497.

14. James, C. C. M., Lassman, L. P. (1964) 'Diastematomyelia, a critical survey of 24 cases submitted to laminectomy.' Archives of Disease in Childhood, 39, 125-130. 
15. Burrows, F. G. G. (1968) 'Some aspects of occult spinal dysraphism: a study of 90 cases.' British Journal of Radiology. 41, 496-507.

16. Eid, K., Hochberg, J., Saunders, D. (1979) 'Skin abnormalities of the back in diastematomyelia.' Plastic and Reconstructive Surgery, 63, 535-539.

17. Perret, G. (1960) 'Symptoms and diagnosis of diastematomyelia.' Neurology, 10, 51-60.

18. Cohen, J., Sledge, C. B. (1960) 'Diastematomyelia: an embryological interpretation with report of a case.' American Journal of Diseases of Children, 100, 257-263.

19. Cowie, T. N. (1952) 'Diastematomyelia: tomography in diagnosis.' British Journal of Radiology. 25, 263-266.

20. Amador, L. V., Hankinson, J., Bigler, J. A. (1955) 'Congenital spinal dermal sinuses.' Journal of Pediatrics, 47, 300-310.

21. Madsen, E. T. (1955) 'Fractures of extremities in newborn.' Acta Obstetrica et Gynecologica Scandinavica, 34, 41-75.

22. Shulman, S. T., Madden, J. D., Esterly, J. R., Shanklin, D. R. (1971) 'Transsection of spinal cord: a rare obstetrical complication of cephalic delivery.' Archives of Disease in Childhood, 46, 291-294.

23. Fahrni, W. H. (1950) 'Neonatal sciatic nerve palsy.' Journal of Bone and Joint Surgery, 32B, 42-49.

24. Braly, B. D. (1965) 'Neonatal arterial thrombosis and embolism.' Surgery, 58, 869-873.

25. Snedecor, S. T., Wilson, H. D. (1949) 'Some obstetrical injuries to the long bones.' Journal of Bone and Joint Surgery, 31A, 378-384.

26. Stern, W. E., Rand, R. W. (1959) 'Birth injuries to the spinal cord.' American Journal of Obstetrics and Gynecology, 78, 498-512.

27. Franken, E. A. (1975) 'Spinal cord injury in the newborn infant.' Pediatric Radiology: 3, $101-104$.

28. Towbin, A. (1969) 'Latent spinal cord and brain stem injury in newborn infants.' Developmental Medicine and Child Neurology, 11, 54-68.

29. Adams, J. H., Cameron, H. M. (1965) 'Obstetrical paralysis due to ischaemia of the spinal cord.' Archives of Disease in Childhood, 40, 93-95.

30. Sherk, H. H., Probst, C. (1975) 'Fractures of the proximal humeral epiphysis.' Orthopedic Clinics of North America. 6, 401-413.

31. Aufdermaur, N. (1974) 'Spinal injuries in juveniles. Necropsy findings in 12 cases.' Journal of Bone and Joint Surgery, 56B, 513-519.

32. Sherk, H. H., Schut, L., Lane, J. M. (1976) 'Fractures and dislocations of the cervical spine in children.' Orthopedic Clinics of North America. 7, 593-604.

33. Taylor, J. C. (1948) 'Breech presentation with hyperextension of the neck and intrauterine dislocation of cervical vertebrae.' American Journal of Obstetrics and Gynecology, 56, 381-385.

34. Knowlton, R. W. (1938) 'The flying foetus.' Journal of Obstetrics and Gynaecology of the British Empire, 45, 834-835.

35. Bresnan, J. J., Abroms, I. F. (1974) 'Neonatal spinal cord transsection secondary to intrauterine hyperextension of the neck in breech presentation.' Journal of Pediatrics, 84, 734-737.

36. Abroms, I. F., Bresnan, J. J., Zuckerman, J. E., Fischer, E. G., Strand, R. (1973) 'Cervical cord injuries secondary to hyperextension of the head in breech presentations.' Obstetrics and Gynecology, 41, 369-378.

37. Bhagwanani, S. G., Price, H. V., Laurence, K. M., Ginz, B. (1973) 'Risks and prevention of cervical cord injury in the management of breech presentation with hyperextension of the fetal head.' American Journal of Obstetrics and Gynecology. 115, 1159-1161.

38. Maekawa, K., Masaki, T., Kokobun, Y. (1976) 'Fetal spinal-cord injury secondary to hyperextension of the neck: no effect of caesarean section.' Developmental Medicine and Child Neurology, 18, $228-232$

39. Towbin, A. (1970) 'Central nervous system damage in the human fetus and newborn infant: mechanical and hypoxic injury incurred in the fetal-neonatal period.' American Journal of Diseases of Children, 119, 529-542.

40. Towbin, A. (1964) 'Spinal cord and brain stem injury at birth.' Archives of Pathology, 77, 620-632.

41. Yates, P. O. (1959) 'Birth trauma to the vertebral arteries.' Archives of Disease in Childhood. 34, 436-441.

42. Jones, L. (1970) 'Birth trauma and the cervical spine.' Archives of Disease in Childhood. 45, 147-154.

43. Allen, J. P. (1970) 'Birth injury to the spinal cord.' Northwestern Medicine, 69, 323-326.

44. Hillman, J. W., Sprofkin, B. E., Parrish, T. F. (1954) 'Birth injury to the cervical spine producing a "cerebral palsy" syndrome.' American Surgeon, 20, 900-906.

45. Norman, M. G., Wedderburn, L. C. W. (1973) 'Fetal spinal cord injury with cephalic delivery.' American Journal of Obstetrics and Gynecology, 42, 355-358.

46. Adler, J. B., Patterson, R. L. (1967) 'Erb's palsy: long-term results of treatment in 68 cases.' Journal of Bone and Joint Surgery, 49A, 1052-1064.

47. Kuhns, L. R., Berger, P. E., Roloff, D. W., Poznanski, A. K., Holt, J. F. (1974) 'Fat thickness in the newborn infant of a diabetic mother.' Radiology, 111, 665-671.

48. Aston, J. W. (1979) 'Brachial plexus birth palsy.' Orthopedics, 2, 594-601.

49. Chung, S. M. K., Nissenbaum, M. N. (1975) 'Obstetrical palsy.' Orthopedic Clinics of North 
America, 6, 393-400.

50. Hensinger, R. N. (1977) 'Orthopedic problems of the shoulder and neck.' Pediatric Clinics of North America, 24, 889-902.

51. Hoffer, M. M., Wickenden, R., Roper, B. (1978) 'Brachial plexus birth palsies. Results of tendon transfers to the rotator cuff.' Journal of Bone and Joint Surgery, 60A, 691-695.

52. Gilles, F. H., French, J. H. (1961) 'Postinjection sciatic nerve palsies in infants and children.' Journal of Pediatrics, 58, 195-204.

53. Curtiss, P. H. (1960) 'Sciatic palsy in premature infants.' Journal of the American Medical Association, 174, 1586-1588.

54. SanAugustin, M., Nitowsky, H. M., Borden, J. N. (1962) 'Neonatal sciatic nerve palsy after umbilical vessel injection.' Journal of Pediatrics, 60, 408-413.

55. Hudson, F. P., McCandless, A., O'Malley, A. (1950) 'Sciatic paralysis in newborn infants.' British Medical Journal. 1, 223-225.

56. Shaw, N. E. (1960) 'Neonatal sciatic palsy from injection into the umbilical cord.' Journal of Bone and Joint Surgery, 42B, 736-741.

57. Askue, W. E., Wong, R. (1952) 'Gangrene of the extremities in the newborn infant. Report of 2 cases.' Journal of Pediatrics, 40, 588-598.

58. Papageorgiou, A., Stern, L. (1972) 'Polycythemia and gangrene of an extremity in a newborn infant.' Journal of Pediatrics. 81, 985-987.

59. Hensinger, R. N. (1975) 'Gangrene of the newborn.' Journal of Bone and Joint Surgery. 57A, $121-123$.

60. Weinberger, M., Haynes, R. E., Morse, T. S. (1972) 'Necrotizing fasciitis in a neonate.' American Journal of Diseases of Children, 123, 591-594.

61. Valderama, E., Gribetiz, I., Strauss, L. (1972) 'Peripheral gangrene in a newborn infant associated with renal and adrenal vein thrombosis. Report of a case in an offspring of a diabetic mother.' Journal of Pediatrics, 80, 101-103.

62. Gilbert, E. F., Hogan, G. R., Stevenson, M. M., Suzuki, H. (1970) 'Gangrene of an extremity in the newborn.' Pediatrics, 45, 469-472.

63. Heffelfinger, M. J., Harrison, E. G. (1971) 'Neonatal gangrene with developmental abnormality of the femoropopliteal artery.' Archives of Pathology, 91, 228-233.

64. Perlmutter, H. D., Wagner, D. H. (1950) 'Arterial thrombosis in the newborn infant.' Journal of Pediatrics, 37, 259-262.

65. Steiner, M. D. (1945) 'Gangrene of an extremity in a newborn child.' American Journal of Obstetrics and Gynecology, 49, 686-690.

66. Manios, S. G., Kanokoudi, F., Miliaras-Vlachakis, M. (1972) 'Gangrene of lower extremities in a newborn infant associated with intravascular coagulation. (Recession of gangrene after heparin therapy.)' Helvetica Paediatrica Acta, 27, 187-192.

67. Gross, R. E. 'Arterial embolism and thrombosis in infancy.' American Journal of Diseases of Children, 70, 61-73.

68 Cartwright, G. W., Schreiner, R. L. (1980) "Major complication secondary to percutaneous radial artery catheterization in the neonate.' Pediatrics, 65, 139-141.

69. Torpin, R. (1965) 'A mniochorionic mesoblastic fibrous strings and amnionic bands.' American Journal of Obstetrics and Gynecology. 91, 65-75.

70. Torpin, R. (1968) Fetal Malformations. Springfield, Ill.: C. C. Thomas.

71. Torpin, R., Faulkner, A. (1966) 'Intrauterine amputation with the missing member found in the fetal membranes.' Journal of the American Medical Association, 198, 185-187.

72. Baker, C. J., Rudolph, A. J. (1971) 'Congenital ring constructions and intrauterine amputations.' American Journal of Diseases of Children, 121, 393-400.

73. Field. J. H.. Krag, D. O. (1973) Congenital constricting bands and congenital amputation of the fingers. Placental studies.' Journal of Bone and Joint Surgery. 55A, 1035-1041.

74. Streeter, G. L. (1930) 'Focal deficiencies in fetal tissues and their relation to intrauterine amputation.' Carnegie Institute. Contributions in Embryology, 22, 1-4.

75. Poswillo, D. (1966) 'Observations of fetal posture and causal mechanisms of congenital deformity of palate, mandible, and limbs.' Journal of Dental Research. 45, 584-596.

76. Cowell, H. R., Hensinger, R. N. (1976) 'The relationship of club foot to congenital annular bands.' In: Bateman, J. E. (Ed.) Foot Science. Philadelphia: W. B. Saunders. pp. 41-46.

77. Trueta, J. (1959) 'The three types of haematogenous osteomyelitis. A clinical and vascular study." Journal of Bone and Joint Surgers. 41B, 671-680.

78. Ogden, J. A., Lister, G. (1975) 'The pathology of neonatal osteomyelitis.' Pediatrics, 55. 474-478.

79. Fox, L., Sprunt, K. (1978) 'Neonatal osteomyelitis.' Pediatrics, 62, 535-542.

80. Morrey, B. F., Banco, A. J., Rhodes, K. H. (1975) 'Septic arthritis in children.' Orthopedic Clinics of North America, 6, 923-934.

81. Morrey, B. F., Peterson, H. A. (1975) 'Hematogenous pyogenic osteomyelitis in children.' Orthopedic Clinics of North America, 6, 9.35-951. 